\title{
Extended Doxycycline Treatment Versus Aspiration of Hydrosalpingeal Fluid in the Management of Patients With Ultrasound Visible Hydrosalpinx Who Refused or Not Eligible to Undergo Salpingectomy Prior to IVF-ET
}

Usama Fouda ( $\nabla$ umfrfouda@yahoo.com )

Cairo University https://orcid.org/0000-0002-5002-4188

Hesham S. Elshaer

Cairo University Kasr Alainy Faculty of Medicine

Sherin M. Sobh

Cairo University

Emad M. Salah

Cairo University Kasr Alainy Faculty of Medicine

Fatma F. Darweesh

Cairo University Kasr Alainy Faculty of Medicine

Ahmed A. Wali

Cairo University Kasr Alainy Faculty of Medicine

Tarek El Husseiny

Cairo University Kasr Alainy Faculty of Medicine

Mohammad A. Taymour

Cairo University Kasr Alainy Faculty of Medicine

\section{Research}

Keywords: Doxycycline, ultrasound, IVF-ET, hydrosalpinx

Posted Date: January 5th, 2021

DOI: https://doi.org/10.21203/rs.3.rs-138894/v1

License: (c) (i) This work is licensed under a Creative Commons Attribution 4.0 International License.

Read Full License 


\section{Abstract}

Background: The purpose of this study was to detect whether antibiotic therapy during IVF-ET cycle is as effective as aspiration of hydrosalpinx fluid under ultrasound guidance in preventing the adverse effect of hydrosalpinx on IVF-ET results.

Methods: During the period between November 2012 and January 2020, patients with ultrasound visible hydrosalpinges undergoing IVF-ET who refused to undergo laparoscopic salpingectomy or not eligible for laparoscopy were advised to receive antibiotic therapy during IVF-ET cycle or to undergo aspiration of hydrosalpinx fluid under ultrasound guidance at the time of ovum pick up. A retrospective analysis was done for the results of IVF-ET cycles of patients who received antibiotic therapy $(n=52)$ or underwent aspiration of hydrosalpinx fluid under ultrasound guidance $(n=76)$. In the aspiration group, the tip of the suction needle was introduced into the hydrosalpinx to aspirate the hydrosalpinx fluid after completing the ovum pick up. In the antibiotic group, doxycycline $(100 \mathrm{mg} / 12 \mathrm{~h})$ was commenced one week before ovum pick up and was continued for another week after ovum pick up.

Results: The implantation, clinical pregnancy, ongoing pregnancy and live birth rates were significantly higher in the aspiration group $(16.67 \%$ Vs. $8.33 \%$, $\mathrm{P}$ value $=0.029,32.89 \%$ Vs. $15.38 \% \mathrm{P}$ value $=0.026$, $30.26 \%$ Vs. $13.46 \%, P$ value $=0.028$ and $28,95 \%$ Vs. $13.46 \% \mathrm{P}$ value $=0.04$ respectively)

Conclusion: The aspiration of hydrosalpinx fluid under ultrasound guidance is more effective than antibiotic therapy in preventing the negative impact of hydrosalpinx on the results of IVF-ET. The results of the current study should be proved by subsequent randomized controlled studies.

\section{Background}

Several prospective and retrospective studies reported that hydrosalpinx has an adverse effect on assisted conception results $(1,2)$. A meta-analysis including 6713 IVF-ET cycles of patients with tubal infertility (5,569 cycles in patients without hydrosalpinx and 1144 cycles in patients with hydrosalpinx) reported that the implantation and clinical pregnancy rates were reduced by $50 \%$ in patients with hydrosalpinx (3).

Since the $90 \mathrm{~s}$, there is agreement by researchers that salpingectomy or proximal tubal occlusion can increase the implantation and pregnancy rates in patients with hydrosalpinx who undergo IVF-ET $(4,5,6)$. However, these procedures are expensive. require hospital admission and general anaesthesia and may be associated with perioperative complications especially in patients with multiple laparotomies or extensive adhesions. Moreover, some patients refuse to undergo these procedures because these procedures remove any chance of spontaneous conception $(6,7)$.

Several authors investigated several treatment modalities such as Essure micro-inserts hysteroscopic tubal occlusion, aspiration of hydrosalpinx under ultrasound guidance and the use of medications such as antibiotics or corticosteroids to prevent the negative impact of hydrosalpinx on the results of IVF-ET 
$(2,8,9)$. Although several studies confirmed that Essure micro-inserts hysteroscopic tubal occlusion and aspiration of hydrosalpinx under ultrasound guidance are effective in the management of patients with hydrosalpinx who undergo IVF-ET $(2,7,10)$. However, aspiration of hydrosalpinx fluid under ultrasound guidance may injure pelvic organs or flare pelvic infection (10). Moreover, Essure micro-inserts hysteroscopic tubal occlusion postpones the IVF-ET cycle for at least 3 months ( to confirm tubal occlusion), and may be associated with complications such as injury of the uterus during insertion, chronic pelvic pain, allergy, menstrual irregularities and device migration. Moreover, it is associated with higher abortion rate compared with other interventions $(11,12)$.

There is only one retrospective study which reported the use of antibiotics in patients with hydrosalpinx who undergo IVF-ET. The study compared the results of IVF-cycles of patients with hydrosalpinx treated with extended doxycycline regimen (100 mg / $12 \mathrm{~h}, 7$ days before ovum pick up and 6 days after ovum pick up) with the results of IVF-cycles of patients with tubal adhesions/proximal tubal block and patients with unexplained infertility /endometriosis. The success of IVF-ET cycles was comparable between the three groups (9).

Till now, no studies have compared the efficacy of aspiration of hydrosalpinx fluid under ultrasound guidance with antibiotic therapy in preventing the adverse effect of hydrosalpinx on IVF-ET results .

The purpose of this study was to detect whether antibiotic therapy is as effective as aspiration of hydrosalpinx fluid under ultrasound guidance in preventing the adverse effect of hydrosalpinx on IVF-ET results.

\section{Methods}

We performed an analysis for the results of IVF-ET cycles of patients with ultrasound visible hydrosalpinx [tubular structure with folded configuration (forming an incomplete septation)] who received antibiotic therapy during IVF-ET cycle or underwent aspiration of hydrosalpinx fluid under ultrasound guidance at the time of ovum pickup in Riyadh fertility and reproductive health center during the period between November 2012 and January 2020.

During the study period, laparoscopic salpingectomy or proximal tubal occlusion were the first management option for patients with ultrasound visible hydrosalpinges. Patients who refused to undergo laparoscopic salpingectomy or proximal tubal occlusion and patients who were not eligible for laparoscopy (i.e. with multiple laparotomies or extensive pelvic adhesions) were advised to receive antibiotic therapy during IVF-ET cycle or to undergo aspiration of hydrosalpinx fluid under ultrasound guidance at the time of ovum pick up. The study protocol was approved by the institutional ethics committee. Each of the patients signed written informed consent to participate in the study.

Exclusion criteria were age less than 18 years or more than 37 years, anti-Müllerian hormone (AMH) less than $0.3 \mathrm{ng} / \mathrm{ml}$, antral follicle count (AFC) less than 6, interstitial uterine fibroid more than $5 \mathrm{~cm}$ in diameter, submucous fibroid, polycystic ovary syndrome (PCOS) and history of habitual abortion. 
The long GnRH agonist protocol was used in all the patients as previously described by Fouda et al (7). Oocyte retrieval was performed 34 to 36 after HCG administration by transvaginal ultrasound guided follicular fluid aspiration. In aspiration group, the tip of the suction needle was introduced into the hydrosalpinx to aspirate the hydrosalpinx fluid after completing the ovum pick up. The aspirated fluid was submitted for bacteriological analysis. In antibiotic group, doxycycline (100 mg/12 h ) was commenced one week before ovum pick up and was continued for another week after ovum pick up.

One to three embryos were transferred under ultrasound guidance 2 to 5 days after ovum pick up. If endometrial fluid was detected at the time of embryo transfer, this fluid was aspirated before embryo transfer. B-subunit HCG was measured in blood two weeks after embryo transfer to diagnose pregnancy. In the aspiration group, transvaginal ultrasound was performed 14 days after embryo transfer to detect recollection of hydrosalpinx fluid. In both groups, transvaginal ultrasound was performed five weeks after embryo transfer to confirm the viability of the fetus and to detect the number of gestational sacs (13). Vaginal progesterone suppositories $400 \mathrm{mg}$ (twice daily) (Prontogest, Marcyrl, Egypt) were given from the day of the HCG administration till the end of the first trimester or negative pregnancy test.

\section{Results}

During the period between November 2012 and January 2020, 72 patients received antibiotic therapy during IVF-ET cycle and 92 patients underwent aspiration of hydrosalpinx fluid under ultrasound guidance. After exclusion of patients who did not meet the inclusion criteria, the antibiotic group included 52 patients and the aspiration group included 76 patients.

Both groups were comparable with respect to age, body mass index (BMI), basal FSH, AMH, number of patients with bilateral hydrosalpinx, duration and type of infertility (Table 1). 
Table 1

Principal characteristics of the patients

\begin{tabular}{|llll|}
\hline & $\begin{array}{l}\text { Aspiration group } \\
(\mathbf{n}=\mathbf{7 6})\end{array}$ & $\begin{array}{l}\text { Antibiotic group } \\
(\mathbf{n}=\mathbf{5 2})\end{array}$ & P value \\
\hline Age (years $)$ & $28.05 \pm 3.66$ & $27.48 \pm 3.88$ & 0.404 \\
\hline Body mass index $\left(\mathrm{Kg} / \mathrm{m}^{2}\right)$ & $27.09 \pm 3.77$ & $26.29 \pm 3.18$ & 0.196 \\
\hline Duration of infertility(years) & $3.55 \pm 1.79$ & $3.15 \pm 1.64$ & 0.196 \\
\hline Type of infertility & & & \\
\hline - Primary & $58 / 76(76.32 \%)$ & $37 / 52(71.15 \%)$ & 0.512 \\
\hline - Secondary & $18 / 76(23.68 \%)$ & $15 / 52(28.85 \%)$ & 0.512 \\
\hline Basal FSH(IU/L) & $6.36 \pm 2.08$ & $6.22 \pm 2.02$ & 0.703 \\
\hline AMH & $2.05 \pm 0.96$ & $1.96 \pm 1.04$ & 0.628 \\
\hline Bilateral hydrosalpinx & $18 / 76(23.68 \%)$ & $13 / 52(25 \%)$ & 0.781 \\
\hline Values are expressed as mean $\pm \mathrm{SD}$ or $\mathrm{n} / \mathrm{n}(\%)$ & & \\
\hline
\end{tabular}

IVF cycle characteristics are shown in Table 2. Both groups were comparable with regard to total consumption of gonadotropins, stimulation duration, number of mature follicles, oocytes retrieved, mature oocytes and embryos transferred. 
Table 2

Outcome of stimulation

\begin{tabular}{|c|c|c|c|}
\hline & $\begin{array}{l}\text { Aspiration group } \\
(n=76)\end{array}$ & $\begin{array}{l}\text { Antibiotic group } \\
(n=52)\end{array}$ & $\begin{array}{l}P \\
\text { value }\end{array}$ \\
\hline Stimulation period(days) & $11.39 \pm 1.19$ & $11.13 \pm 1.67$ & 0.336 \\
\hline Consumed HP-uFSH units & $2607 \pm 517$ & $2744 \pm 711$ & 0.239 \\
\hline $\begin{array}{l}\text { Follicles } \geq 17 \mathrm{~mm} \text { on the day of HCG } \\
\text { administration }\end{array}$ & $12.16 \pm 3.69$ & $13.23 \pm 4.63$ & 0.166 \\
\hline Retrieved oocytes & $11.09 \pm 3.34$ & $12.15 \pm 4.65$ & 0.16 \\
\hline Metaphase II oocytes & $9.76 \pm 3.34$ & $10.98 \pm 4.54$ & 0.102 \\
\hline Two pronucleate embryos & $7.92 \pm 3.12$ & $8.44 \pm 3.78$ & 0.413 \\
\hline Fertilization rate & $\begin{array}{l}602 / 742( \\
81.13 \%)\end{array}$ & $439 / 571(76.88 \%)$ & 0.06 \\
\hline No. of embryos transferred & $2.61 \pm 0.49$ & $2.54 \pm 0.5$ & 0.458 \\
\hline \multicolumn{4}{|l|}{ No of embryos transferred } \\
\hline - Day 2 & 14 & 10 & 0.653 \\
\hline - Day 3 & 166 & 106 & \\
\hline - Day 5 & 18 & 16 & \\
\hline Grade I \& II embryos /transferred embryos & $\begin{array}{l}121 / 198( \\
61.11 \%)\end{array}$ & $88 / 132(66.7 \%)$ & 0.305 \\
\hline
\end{tabular}

The implantation rate was $16.67 \% \%$ in the aspiration group and $8.33 \%$ in the antibiotic group $(P=0.029)$. The clinical pregnancy and the ongoing pregnancy rates were significantly higher in the aspiration group $(32.89 \%$ Vs. $15.38 \% \mathrm{P}$ value $=0.026,30.26 \%$ Vs. $13.46 \%, \mathrm{P}$ value $=0.028$, respectively $)$. The live birth rate was $28,95 \%$ in the aspiration group and $13.46 \%$ in the antibiotic group ( $P$ value $=0.04)($ Table 3$)$. 
Table 3

Treatment outcomes

\begin{tabular}{|llll|}
\hline & $\begin{array}{l}\text { Aspiration group } \\
(\mathrm{n}=76)\end{array}$ & $\begin{array}{l}\text { Antibiotic } \\
(\mathrm{n}=52)\end{array}$ & group \\
\hline Clinical pregnancy rate & $25 / 76(32.89 \%)$ & $8 / 52(15.38 \%)$ & 0.026 \\
\hline Ongoing pregnancy rate & $23 / 76(30.26 \%)$ & $7 / 52(13.46 \%)$ & 0.028 \\
\hline Live birth rate & $22 / 76(28,95 \%)$ & $7 / 52(13.46 \%)$ & 0.04 \\
\hline Implantation rate & $33 / 198(16.67 \%)$ & $11 / 132(8.33 \%)$ & 0.029 \\
\hline Spontaneous abortion rate $\mathrm{n} / \mathrm{IUP}$ & $2 / 25(8 \%)$ & $1 / 8(12.5 \%)$ & 0.7 \\
\hline Values are expressed as $\mathrm{n} / \mathrm{n}(\%)$. IUP= intrauterine pregnancy & \\
\hline
\end{tabular}

In the aspiration group, when the patients were scanned at the time of embryo transfer, four patients had recollection of hydrosalpinx fluid and endometrial fluid collection and four patients had only recollection of hydrosalpinx fluid. Moreover, ultrasound scan performed 14 days after embryo transfer detected the recollection of hydrosalpinx fluid in 20 patients. In the antibiotic group, when the patients were scanned at the time of embryo transfer, eight patients had endometrial fluid collection.

Table 4 shows the reproductive outcome of the subgroups of patients in the aspiration group. The implantation, pregnancy and live birth rates were non significantly higher in the patients with no recollection of hydrosalpinx fluid compared with the patients with recollection of hydrosalpinx fluid. The two subgroups were comparable with respect to age, early follicular phase FSH, percentage of patients with bilateral hydrosalpinx and number and grade of embryos transferred. None of the patients with endometrial fluid collection on the day of embryo transfer become pregnant. 
Table 4

Reproductive outcomes of the subgroups of patients in the aspiration group

\begin{tabular}{|llll|}
\hline & $\begin{array}{l}\text { Implantation } \\
\text { rate }\end{array}$ & $\begin{array}{l}\text { Clinical } \\
\text { pregnancy } \\
\text { rate }\end{array}$ & Live birth rate \\
\hline $\begin{array}{l}\text { No recollection of hydrosalpinx fluid within the first } \\
14 \text { days + no endometrial fluid collection }(n=56)\end{array}$ & $\begin{array}{l}28 / 146 \\
(19.18 \%)\end{array}$ & $\begin{array}{l}21 / 56 \\
(37.5 \%)\end{array}$ & $19 / 55(34.55 \%)$ \\
\hline $\begin{array}{l}\text { Recollection of hydrosalpinx fluid within the first } 14 \\
\text { days } \pm \text { endometrial fluid collection ( } \mathrm{n}=20)\end{array}$ & $5 / 52(9.62 \%)$ & $\begin{array}{l}4 / 20 \\
(20 \%)\end{array}$ & $3 / 20(15 \%)$ \\
\hline $\begin{array}{l}\text { Recollection of hydrosalpinx fluid within the first } 14 \\
\text { days + no endometrial fluid collection ( } \mathrm{n}=16)\end{array}$ & $5 / 42(11.9 \%)$ & $\begin{array}{l}4 / 16 \\
(25 \%)\end{array}$ & $3 / 16(18.75 \%)$ \\
\hline $\begin{array}{l}\text { Recollection of hydrosalpinx fluid within the first } 14 \\
\text { days + endometrial fluid collection ( } \mathrm{n}=4)\end{array}$ & $0 / 10(0 \%)$ & $0 / 4(0 \%)$ & $0 / 4(0 \%)$ \\
\hline $\begin{array}{l}\text { There were no significant differences between the four subgroups. } \\
\text { Values are expressed as } \mathrm{n} / \mathrm{n} \text { (\%). }\end{array}$ & & & \\
\hline
\end{tabular}

Flaring of pelvic infection, peritonitis or injury of pelvic organs were not reported in patients in the aspiration group. Cultures from the hydrosalpinx fluid were negative for bacterial growth.

\section{Discussion}

The current study revealed that the aspiration of hydrosalpinx fluid under ultrasound guidance is more effective than antibiotic treatment in preventing the negative impact of hydrosalpinx on the results of IVFET .

Several researchers suggested that the flow of hydrosalpinx fluid into the endometrial cavity is the reason of the negative impact of hydrosalpinx on the results of IVF-ET (10). Two studies revealed that the presence of hydrosalpinx decreases the expression of uterine receptivity markers (Homeobox A10, $\beta$ integrin and leukemia inhibitory factor) and that salpingectomy increases the expression of these markers $(14,15)$.

Several authors suggested that the inflammatory process in the hydrosalpinx caused by bacteria ( mainly Chlamydia trachomatis ) could extend to the endometrium thought the flow of hydrosalpinx fluid into endometrial cavity or through lymphatics or blood vessels (9). It was postulated that the inflammatory mediators released by chronic inflammatory cells present in hydrosalpinx may cause embryonic damage or alter endometrial receptivity (16.17).

The results of the current study suggested that antibiotic therapy is not effective in the prevention of the adverse effect of hydrosalpinx on IVF-ET outcome. In contrast to our results, a small retrospective study comparing the outcome of IVF-ET cycles of patients with hydrosalpinx who were treated with extended 
doxycycline regimen with the outcome of IVF-ET cycles of patients with adhesions / proximal tubal block and patients with endometriosis / unexplained infertility, revealed that the success of IVF-ET cycles was comparable between the three groups (9).

The results of the current study are in accordance with several studies which reported that the aspiration of hydrosalpinx fluid at the time of ovum pick up is a simple, safe and inexpensive procedure that can prevent the negative impact of hydrosalpinx on the results of IVF-ET $(2,7,18)$. Moreover, the data presented in the current study suggest that the aspiration of hydrosalpinx fluid under ultrasound guidance is less effective in the management of patients with rapid recollection of hydrosalpinx fluid and ineffective in the management of patients with endometrial fluid collection on the day of embryo transfer.

Two randomized controlled trials compared aspiration of hydrosalpinx fluid under ultrasound guidance at the time of ovum pick up with no intervention in patients with ultrasound visible hydrosalpinges who undergo IVF-ET. Fouda et al reported that the implantation, clinical pregnancy, and ongoing pregnancy rates were higher in the aspiration group $(18.70 \%$ Vs. $8.33 \%, 31.48 \%$ Vs. $13.21 \%$ and $27.78 \%$ Vs $9.43 \%$ respectively) (2). Hammadieh et al reported that the chemical pregnancy rate was $43.8 \%$ in the aspiration group and $20.6 \%$ in the control group ( $P$ value $=0.04$ ). The clinical pregnancy rate was higher in the aspiration group but the difference failed to reach statistical significance $(31.3 \%$ vs. $17.6 \%, P=0.20)(18)$.

In a randomized controlled trial including 160 patients with ultrasound visible hydrosalpinx, Fouda et al compared the effectiveness of aspiration of hydrosalpinx fluid under ultrasound guidance with salpingectomy in the management of patients with hydrosalpinges who undergo IVF-ET. Rapid recollection of hydrosalpinx fluid (i.e. within 2 weeks after embryo transfer) was noticed in $34.21 \%$ of the patients in the aspiration group. The clinical pregnancy and the implantation rates were higher in salpingectomy group compared with the subgroup of patients with rapid recollection of hydrosalpinx fluid $(42.67 \%$ vs. $19.23 \%$ and $18.95 \%$ vs. $7.58 \%$, respectively). On the other hand, the clinical pregnancy and the implantation rates were comparable between the salpingectomy group and the subgroup of patients with no recollection of hydrosalpinx fluid ( $42.67 \%$ vs. $34 \%$ and $18.95 \%$ vs. $15.5 \%$ respectively)(7).

In the current study, four patients in the aspiration group and eight patients in the antibiotic group had endometrial fluid collection on the day of embryo transfer. None of those patients conceived. The results of the current study are in accordance with numerous studies which reported that the subgroup of patients with endometrial fluid collection on the day of embryo transfer has the lowest pregnancy rates $(2,7,19,20)$. Several authors suggested that the ideal treatment option for this subgroup of patients is to cryopreserve the embryos and to transfer the embryos in subsequent cycles after performing salpingectomy or proximal tubal occlusion (21)(7).

The major weakness of the current study is the retrospective design. However, our study has several strengths. Our study is largest study which reported the use of antibiotic therapy in patients with ultrasound visible hydrosalpinges who undergo IVF-ET. Moreover, the current study is the first study which compared the efficacy of antibiotic therapy with aspiration of hydrosalpinx fluid under ultrasound guidance in the management of patients with ultrasound visible hydrosalpinges who undergo IVF-ET. 


\section{Conclusion}

In conclusion, the aspiration of hydrosalpinx fluid under ultrasound guidance is more effective than antibiotic therapy in preventing the negative impact of hydrosalpinx on the results of IVF-ET. The results of the current study should be proved by subsequent randomized controlled studies.

\section{Abbreviations}

AFC: Antral follicle count

AMH: Anti-Müllerian hormone

ART: Assisted reproductive techniques

FSH: Follicle stimulating hormone

ICSI: Intra cytoplasmatic sperm injection

IVF-ET: In vitro fertilization embryo transfer.

IUP: intrauterine pregnancy

PCOS: Polycystic ovary syndrome

\section{Declarations}

\section{Ethics approval and consent to participate}

The study protocol was approved by the ethics committee of Riyadh fertility and reproductive health center.

Informed consent was obtained from all the patients.

Declaration of interest

No conflict of interests

\section{Grants}

No grants

\section{Acknowledgements}

No 
All data from the current study supporting the conclusions are presented in the article.

\section{Consent for publication}

Not applicable.

\section{Authors contribution}

All the authors [Usama M. Fouda ,Hesham S. Elshaer ', Sherin M. Sobh , Emad M. Salah, Fatma F. Darweesh, Ahmed A. Wali , Tarek El Husseiny and Mohammad A. Taymour ] participated in the conception, design of the work ,the acquisition, analysis, interpretation of data, have drafted the work and substantively revised it

\section{References}

1. Kassabji M, Sims JA, Butler L, Muasher SJ. Reduced pregnancy outcome in patients with unilateral or bilateral hydrosalpinx after in vitro fertilization. Eur J Obstet Gynecol Reprod Biol.1994,56(2):12932.

2. Fouda UM, Sayed AM. Effect of ultrasound-guided aspiration of hydrosalpinx fluid during oocyte retrieval on the outcomes of in vitro fertilisation-embryo transfer: a randomised controlled trial (NCT01040351). Gynecol Endocrinol.2011,27(8):562-7.

3. Zeyneloglu HB, Arici A, Olive DL. Adverse effects of hydrosalpinx on pregnancy rates after in vitro fertilization - embryo transfer. Fertil Steril.1998, 70:492-9.

4. Strandell A, Lindhard A, Waldenstrom U, Thorburn J, Janson PO, Hamberger L .Hydrosalpinx and IVF outcome: a prospective, randomized multicentre trial in Scandinavia onsalpingectomy prior to IVF. Hum Reprod.1999, 14:2762-2769.

5. Moshin V, Hotineanu A. Reproductive outcome of the proximal tubal occlusion prior to IVF in patients with hydrosalpinx. Hum Reprod.2006, 21:i193-4.

6. Johnson N, van Voorst S, Sowter MC, Strandell A, Mol BW. Surgical treatment for tubal disease in women due to undergo in vitro fertilisation. Cochrane Database Syst Rev.2010,20(1):CD002125.

7. Fouda UM, Sayed AM, Abdelmoty HI, Elsetohy KA. Ultrasound guided aspiration of hydrosalpinx fluid versus salpingectomy in the management of patients with ultrasound visible hydrosalpinx who undergo IVF-ET: a randomized controlled trial. BMC Womens Health. 2015,15:21.

8. Matorras R, Rabanal A, Prieto B, Diez S, Brouard I, Mendoza R, et al. Hysteroscopic hydrosalpinx occlusion with Essure device in IVF patients when salpingectomy or laparoscopy is contraindicated. Eur J Obstet Gynecol Reprod Biol.2013,169(1):54-9.

9. Hurst BS, Tucker KE, Awoniyi CA, Schlaff WD. Hydrosalpinx treated with extended doxycycline does not compromise the success of in vitro fertilization. Fertil Steril.2001, 75:1017-1019.

10. D'Arpe S, Franceschetti S, Caccetta J, Pietrangeli D, Muzii L, Panici PB. Management of hydrosalpinx before IVF: a literature review. J Obstet Gynaecol.2015,35(6):547-50. 
11. Arora P, Arora R, Cahill D. Essure ${ }^{\circledR}$ for management of hydrosalpinx prior to in vitro fertilisation-a systematic review and pooled analysis. BJOG.2014, 121(5):527-36.

12. Barbosa MW, Sotiriadis A, Papatheodorou SI, Mijatovic V, Nastri CO, Martins WP. High miscarriage rate in women treated with Essure ${ }^{\circledR}$ for hydrosalpinx before embryo transfer: a systematic review and meta-analysis. Ultrasound Obstet Gynecol. 2016,48(5):556-565.

13. Fouda U, Sayed A. Extended high dose letrozole regimen versus short low dose letrozole regimen as an adjuvant to gonadotropin releasing hormone antagonist protocol in poor responders undergoing IVF-ET*. Gynecological Endocrinology .2011,27(12) 1018-1022.

14. Meyer WR, Castelbaum AJ, Somkuti S, Sagoskin AW, Doyle M, Harris JE, et al. Hydrosalpinges adversely affect markers of endometrial receptivity. Hum Reprod.1997,12:1393-1398.

15. Seli E, Kayisli UA, Cakmak H, Bukulmez O, Bildirici I, Guzeloglu-Kayisli O, et al. Removal of hydrosalpinges increases endometrial leukaemia inhibitory factor (LIF) expression at the time of the implantation window. Hum Reprod. 2005,20(11):3012-7.

16. David A, Garcia CR, Czernobilsky B. Human hydrosalpinx. Histologic study and chemical composition of fluid. Am J Obstet Gynecol. 1969,105(3):400-11.

17. Bedaiwy MA, Goldberg JM, Falcone T, Singh M, Nelson D, Azab H, et al. Relationship between oxidative stress and embryotoxicity of hydrosalpinx fluid. Hum Reprod.2002, 17(3):601-4.

18. Hammadieh N, Coomarasamy A, Ola B, Papaioannou S, Afnan M, Sharif K. Ultrasound-guided hydrosalpinx aspiration during oocyte collection improves pregnancy outcome in IVF: a randomized controlled trial. Hum Reprod. 2008, 23: 1113-1117.

19. Chien LW, Au HK, Xiao J, Tzeng CR. Fluid accumulation within the uterine cavity reduces pregnancy rates in women who undergo IVF. Hum Reprod.2002, 17:351-356.

20. Akman MA, Erden HF, Bahceci M. Endometrial fluid visualized through ultrasonography during ovarian stimulation in IVF cycles impairs the outcome in tubal factor, but not PCOS, patients. Hum Reprod .2005,20:906-909.

21. Sharara FI, McClamrock HD. Endometrial fluid collection in women with hydrosalpinx after human chorionic gonadotrophin administration: a report of two cases and implications for management. Hum Reprod. 1997,12(12):2816-9 